\title{
Correction to: A direct displacement-based seismic design method using a MDOF equivalent system: application to $R / C$ framed structures
}

\author{
Edmond V. Muho ${ }^{1} \cdot$ Jiang Qian ${ }^{1} \cdot$ Dimitri E. Beskos ${ }^{1,2}$
}

Published online: 8 June 2020

(c) Springer Nature B.V. 2020

\section{Correction to: Bulletin of Earthquake Engineering https://doi.org/10.1007/s10518-020-00857-5}

This erratum is published as proofing errors were introduced in Fig. 1 during typesetting, which needs to be correctly read as follows:

The original article has thus been updated with the corrections.

The original article can be found online at https://doi.org/10.1007/s10518-020-00857-5.

Dimitri E. Beskos

dimisof@hotmail.com

1 Department of Disaster Mitigation for Structures, College of Civil Engineering, Tongji University, Shanghai 200092, China

2 Department of Civil Engineering, University of Patras, 26500 Patras, Greece 


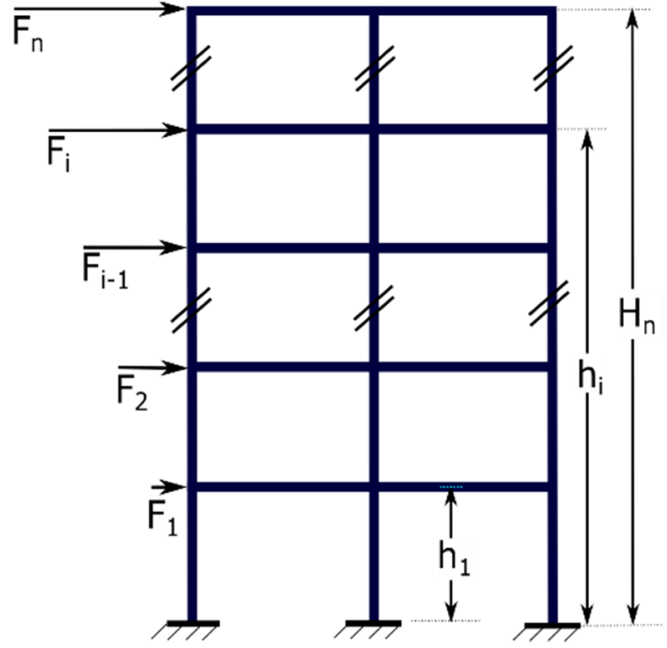

(a)

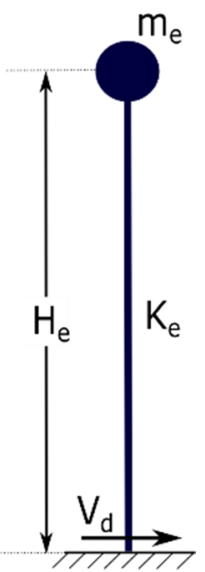

(b)

Fig. 1 The MDOF structure (a) and its SDOF representation in the original DDBD (Sullivan et al. 2012) $\operatorname{method}(\mathbf{b})$

Publisher's Note Springer Nature remains neutral with regard to jurisdictional claims in published maps and institutional affiliations. 